Jurnal Kesmas Asclepius

Volume 1, Nomor 2, Desember 2019

e-ISSN: 2684-8287

p-ISSN: 2656-8926

DOI: https://doi.org/10.31539/jka.v1i2.919

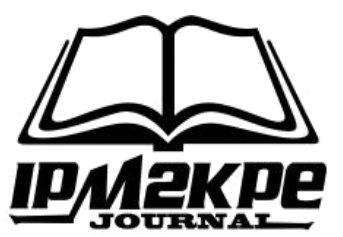

\title{
DETERMINAN KEPATUHAN MINUM OBAT PASIEN TUBERKULOSIS PARU
}

\author{
Christine Vita Gloria ${ }^{1}$, Zulmeliza Rasyid ${ }^{2}$, Sherly Vermita $W^{3}$, \\ Elmia Kursani ${ }^{4}$, Bizanti Umayyah ${ }^{5}$ \\ Sekolah Tinggi Ilmu Kesehatan Hang Tuah ${ }^{1,2,3,4,5}$ \\ christinevgp@gmail.com ${ }^{1}$
}

\begin{abstract}
ABSTRAK
Penelitian ini bertujuan untuk melihat apakah determinan terkait dengan kepatuhan pengobatan untuk pasien tuberkulosis paru di pusat kesehatan 2019. Jenis penelitian ini adalah observasional kuantitatif dengan desain cross sectional. Hasil penelitian menunjukkan bahwa dengan Nilai P 0,05, terdapat hubungan yang signifikan antara pengetahuan (Nilai $\mathrm{P}=0,005$ dan $\mathrm{POR}=14,276$ ), sikap (Nilai $\mathrm{P}=0,506$ dan $\mathrm{POR}=$ 1,615), dukungan keluarga (Nilai $\mathrm{P}=0,038$ dan $\mathrm{POR}=1,961$ ), peran petugas kesehatan (Nilai $\mathrm{P}=0,026$ dan $\mathrm{POR}=4,440$ ) dengan obat kepatuhan untuk pasien tuberkulosis paru. Simpulan, dari 4 variabel terdapat 3 variabel yang berhubungan dengan kepatuhan minum obat TB Paru di Wilayah Kerja Puskesmas Siak Hulu II yaitu pengetahuan, dukungan keluarga,dan peran petugas kesehatan dan 1 variabel yang tidak berhubungan yaitu sikap.
\end{abstract}

Kata Kunci: Ketaatan, Obat, Tuberkulosis Paru

\begin{abstract}
This study aims to see whether the determinants are related to treatment compliance for pulmonary tuberculosis patients at the 2019 health center. This type of research is a quantitative observational cross-sectional design. The results showed that with a $P$ value of 0.05, there was a significant relationship between knowledge ( $P$ value $=0.005$ and $P O R=14.276)$, attitudes $(P$ value $=0.506$ and $P O R=1.615)$, family support $(P$ value $=0.038$ and $P O R=1,961)$, the role of health workers $(P$ values $=0.026$ and POR $=4.440$ ), with medication adherence for pulmonary tuberculosis patients. Conclusions, of the 4 variables there are 3 variables related to adherence to taking pulmonary TB drugs in the Work Area of the Siak Hulu II Health Center, namely knowledge, family support, and the role of health workers and 1 unrelated variable, attitude.
\end{abstract}

Keywords: Obedience, Medicine, Lung Tuberculosis 


\section{PENDAHULUAN}

Tuberkulosis Paru (TB Paru) merupakan penyakit menular yang disebabkan oleh infeksi bakteri mycobacterium tuberculosis. Sampai saat ini masih merupakan salah satu masalah kesehatan masyarakat di dunia. Pengobatan tuberkulosis memerlukan waktu yang relatif panjang dengan dua tahap, yaitu tahap awal (intensif) dan tahap lanjutan (Suryadi, 2019). Kepatuhan penderita sangat dibutuhkan untuk kesembuhan pasien tuberkulosis paru, jika pasien TB Paru tidak patuh minum obat atau sampai putus berobat maka akan menyebabkan pasien carier, sehingga akan menularkan penyakit TB Paru ke orang lain disekitarnya (Indrawaty, 2012).

TB Paru menjadi masalah utama kesehatan dunia, diperkirakan 95\% kasus TB Paru dan $98 \%$ kematian akibat TB Paru terjadi di negara berkembang. Maka dapat disimpulkan tingginya penderita TB Paru dapat dikolerasikan dengan pengobatan yang kompleks, dimana terapi menjadi permasalahan utama bagi pasien. Selain itu informasi yang tidak lengkap dan tidak ada penjelasan terus menerus menjadi kendala pasien untuk pengobatan. Pasien TB Paru dapat dikatakan sembuh apabila mengikuti prosedur pengobatan selama 6 bulan tanpa terputus (Kemenkes, 2014).

Data World Health Organization (WHO) tahun 2017 menunjukkan bahwa jumlah kasus baru TB paru pada tahun 2015 mencapai 10,4 juta jiwa meningkat dari sebelumnya hanya 9,6 juta jiwa. Adapun jumlah kasus TB paru pada tahun 2016 mencapai 11,5 juta jiwa meningkat dari tahun sebelumnya hanya 10,4 juta jiwa. Adapun jumlah temuan TB Paru terbesar adalah di India sebanyak 2,8 juta kasus, diikuti Indonesia sebanyak 1,02 juta kasus dan Tiongkok sebanyak 918 ribu kasus. Berdasarkan laporan WHO tahun 2017 terjadi 1.020.000 kasus di Indonesia.

Menurut data Global Report Tuberculosis tahun 2017 secara global kasus TB Paru sebesar 6,3 juta, setara dengan 61\% dari insiden tuberkulosis (10,4 juta). Tuberkulosis tetap menjadi 10 penyebab kematian tertinggi di dunia dan kematian tuberkulosis secara global diperkirakan 1,3 juta pasien (WHO, Global Tuberculosis Report, 2017). Pengobatan TB Paru tahun 2017 sebanyak 42,8\% meningkat dibandingkan pada tahun 2016 sebesar 35,8\%, angka keberhasilan pengobatan TB Paru sebanyak 85,7\% dan angka kesembuhan 85,0\% (Kemenkes RI, 2018).

Berdasarkan data Kementrian Kesehatan RI (2018) di Indonesia pada tahun 2017 jumlah kasus TB Paru sebanyak 420.994 kasus. Berdasarkan jenis kelamin, jumlah kasus baru TB Paru tahun 2017 dengan jenis kelamin laki-laki 1,4 kali lebih besar dibandingkan perempuan. Proses pengobatan lengkap pasien TB Paru sebanyak 43,1\%, pasien sembuh sebanyak $42,0 \%$,pasien hilang pengamatan $5,4 \%$, pasien pindah $4,0 \%$, pasien tidak dievaluasi 2,7\%, pasien meninggal 2,5\%,pasien yang gagal berobat sebanyak 0,4\% se Indonesia (Kemenkes RI, 2018).

Data dari ditjen pencegahan dan pengendalian penyakit menular Kemenkes RI (2018) jumlah kasus TB Paru di Riau sebanyak 6.739 kasus. Berdasarkan jenis kelamin laki-laki 4.260 dan perempuan 2.479. Jumlah pasien yang berhasil dalam pengobatan sebanyak 4.190(67,94\%), angka kesembuhan sebanyak $2.575(61,46 \%)$ dan angka pengobatan lengkap hanya sebanyak $1.615(38,54)$ se Riau. Berdasarkan data dari Dinas Kesehatan Kabupaten Kampar pada tahun 2018 jumlah kasus penyakit tuberkulosis paru sebanyak 691 kasus dengan angka kematian pasien TB Paru sebanyak 10 orang se Puskesmas Kabupaten Kampar.

Berdasarkan data dari Puskesmas Siak Hulu II pada tahun 2018 terdapat BTA (+) sebanyak 71 orang dengan suspek TB Paru sebanyak 150 orang dan angka kematian pasien TB Paru sebanyak 1 orang di Puskesmas Siak Hulu II tahun 2018, sedangkan 
angka tidak patuh minum obat di Puskesmas Siak Hulu II sebanyak 40\% atau 28 orang. Berdasarkan data dari Program Penanggulangan TB Paru di Puskesmas Siak Hulu II didapatkan pasien TB Paru yang DO (Droup Out) penderita TB Paru sebanyak 21 orang kasus TB Paru tahun 2018 dan 2019. Hasil wawancara dengan pengelola TB Paru di Puskesmas bahwa pasien DO adalah pasien dari tahap lanjutan, pasien kebanyakan tidak datang 1 bulan sebelum berakhir pengobatan dengan pasien merasa sudah sembuh dan dahak tidak ada lagi.

Penyebab dari ketidakberhasilan pengobatan TB Paru adalah kepatuhan pasien selama pengobatan. Menurut penelitian Shalahuddin \& Sukmawan (2018) menunjukkan bahwa pengetahuan merupakan faktor yang berhubungan dengan kepatuhan minum obat TB Paru dengan nilai P 0,000 (OR : 13,375). Menurut penelitian Fitri et al., (2018) sikap pasien TB Paru merupakan faktor yang mempengaruhi kepatuhan pasien TB Paru minum obat di Wilayah Kerja Puskesmas Sadabuan Kota Padang Sidimpuan dengan nilai $\mathrm{p}=0,000$.

Pengetahuan seseorang berhubungan dengan perilaku seseorang, jika pengetahuan seseorang rendah maka perilaku seseorang akan cenderung ke arah yang tidak baik begitu juga sebaliknya jika pengetahuan seseorang tinggi maka perilaku akan cenderung lebih baik. Dalam penelitian ini diketahui bahwa responden tidak mengetahui cara pengobatan TB paru dan tahap minum obat TB paru.

Menurut penelitian Pitters et al., (2018) dukungan keluarga memiliki hubungan dengan kepatuhan minum obat pada pasien tuberculosis paru di Puskesmas Ranotana Weru, dimana $88 \%$ pasien yang tidak patuh berobat memiliki dukungan keluarga yang kurang baik. Sehingga ada hubungan antara dukungan keluarga dengan kepatuhan minum obat pada pasien tuberculosis paru di Puskesmas Ranotana Weru (P value : 0,000). Dari penelitian Suryadi et al., (2019) diperoleh nilai $\mathrm{p}=0,000$ dengan OR: 8,320 yang berarti ada hubungan peran petugas kesehatan dengan kepatuhan minum obat tuberculosis paru di wilayah kerja Puskesmas Siko Kota Ternate.

Hasil survei awal peneliti di Wilayah Kerja Puskesmas Siak Hulu II yang dilakukan terhadap 8 orang pasien penderita TB Paruyang terdiri dari 5 orang pasien yang menderita TB Paru yang patuh berobat sedangkan 3 orang yang tidak patuh minum obat TB Paru. Peneliti menemukan bahwa masih ada pasien yang tidak patuh minum obat TB Paru karena sudah merasa sembuh dan pasien yang tidak mengetahui tahap pengobatan TB Paru, pasien menyatakan bahwa TB Paru adalah batuk biasa saja dan tidak memerlukan pemeriksaan terus-menerus. Berdasarkan hasil wawancara yang dilakukan oleh peneliti diperoleh gambaran sikap yang negatif terhadap pengobatan TB Paru yaitu anggapan penyakit TB paru sudah sembuh dan tidak perlu berobat selama 6 bulan. Di samping itu 5 dari 8 orang pasien menyatakan keluarga kurang mendukung pengobatan TB Paru serta petugas kesehatan kurang berperan dengan baik selama proses pengobatan pasien TB Paru.

\section{METODE PENELITIAN}

Jenis penelitian ini adalah analitik observasional dengan pendekatan kuantitatif dengan desain penelitian CrossSectional yaitu penelitian untuk melihat hubungan variabel independen dan dependen sehingga diperoleh informasi tentang determinan kepatuhan minum obat pasien Tuberkulosis Paru di wilayah kerja Puskesmas Siak Hulu II tahun 2019. 


\section{HASIL PENELITIAN}

Tabel. 1

Distribusi Frekuensi Responden Berdasarkan Variabel Dependen dan Independen

\begin{tabular}{clcc}
\hline No. & \multicolumn{1}{c}{ Variabel } & Frekuensi (n) & Persentase (\%) \\
\hline 1 & Kepatuhan Minum Obat & & \\
& Tidak Patuh & 24 & 33,8 \\
& Patuh & 47 & 66,2 \\
& Total & 71 & 100 \\
2 & Pengetahuan & & \\
& Rendah & 52 & 73,2 \\
& Tinggi & 19 & 26,8 \\
& Total & 71 & 100 \\
3 & Sikap & & \\
& Negatif & 42 & 59,2 \\
& Positif & 29 & 40,8 \\
& Total & 71 & 100 \\
Dukungan Keluarga & & \\
& Tidak Ada & 30 & 42,3 \\
& Ada & 41 & 57,7 \\
& Total & 71 & 100 \\
& Peran Petugas Kesehatan & & \\
& Tidak Berperan & 27 & 38,0 \\
& Berperan & 44 & 62,0 \\
& Total & 71 & 100 \\
\hline
\end{tabular}

Berdasarkan tabel 1 dapat diketahui distribusi frekuensi kepatuhan minum obat terdiri dari 47 orang $(66,2 \%)$ patuh sedangkan sebanyak 24 orang $(33,8 \%)$ responden tidak patuh minum obat. Berdasarkan variabel independen pengetahuan, responden yang memiliki pengetahuan rendah sebanyak 52 orang $(73,2 \%)$ dan responden yang memiliki pengetahuan tinggi sebanyak 19 orang $(26,8 \%)$. Berdasarkan sikap, sebanyak 42 orang $(59,2 \%)$ memiliki sikap negatif dan 29 orang $(40,8 \%)$ memiliki sikap positif. Berdasarkan dukungan keluarga, sebanyak 30 orang (42,3\%) tidak memiliki dukungan keluarga dan sebanyak 41 orang $(57,7 \%)$ memperoleh dukungan keluarga. Berdasarkan peran petugas kesehatan, sebanyak 27 orang $(38,0 \%)$ menyatakan petugas kesehatan tidak berperan sedangkan sebanyak 44 orang $(62,0 \%)$ menyatakan petugas kesehatan berperan.

\section{Analisis Bivariat}

\section{Hubungan Pengetahuan dengan Kepatuhan Minum Obat TB Paru}

Tabel. 2

Hubungan Pengetahuan dengan Kepatuhan Minum Obat TB Paru

\begin{tabular}{|c|c|c|c|c|c|c|c|c|}
\hline \multirow{3}{*}{ Pengetahuan } & \multicolumn{4}{|c|}{ Kepatuhan Minum Obat } & \multirow{2}{*}{\multicolumn{2}{|c|}{ Total }} & \multirow{3}{*}{$P$ Value } & \multirow{3}{*}{ POR CI 95\% } \\
\hline & \multicolumn{2}{|c|}{ Tidak Patuh } & \multicolumn{2}{|c|}{ Patuh } & & & & \\
\hline & $\mathrm{n}$ & $\%$ & $\mathrm{n}$ & $\%$ & $\mathrm{n}$ & $\%$ & & \\
\hline Rendah & 23 & 44,2 & 29 & 55,8 & 52 & 100 & \multirow{3}{*}{0,005} & \multirow{3}{*}{$\begin{array}{c}14,276(1,772 \\
115,04)\end{array}$} \\
\hline Tinggi & 1 & 5,8 & 18 & 94,7 & 19 & 100 & & \\
\hline Total & 24 & 33,8 & 47 & 66,2 & 71 & 100 & & \\
\hline
\end{tabular}


Berdasarkan tabel 2 diperoleh bahwa dari 52 responden dengan pengetahuan rendah terdapat $23(44,2 \%)$ responden yang tidak patuh minum obat sedangkan dari 19 responden dengan pengetahuan tinggi terdapat $1(5,3 \%)$ responden yang tidak patuh minum obat. Hasil uji statistik chi square diperoleh $p$ value $=0,005$ maka dapat disimpulkan bahwa ada hubungan yang signifikan antara pengetahuan dengan kepatuhan minum obat. Diperoleh nilai POR 14,276 (1,772 - 115,040) artinya responden dengan pengetahuan rendah berpeluang 14 kali untuk tidak patuh minum obat dibandingkan responden dengan pengetahuan yang tinggi.

\section{Hubungan Sikap dengan Kepatuhan Minum Obat TB Paru}

Tabel. 3

Hubungan Sikap dengan Kepatuhan Minum Obat TB Paru

\begin{tabular}{ccccccccc}
\hline \multirow{2}{*}{ Sikap } & \multicolumn{4}{c}{ Kepatuhan Minum Obat } & & \multirow{2}{*}{ Total } & \multirow{2}{*}{ P Value } & POR CI 95\% \\
\cline { 2 - 6 } & \multicolumn{2}{c}{ Tidak Patuh } & \multicolumn{2}{c}{ Patuh } & & \multicolumn{2}{c}{$\%$} & \\
\cline { 2 - 6 } & $\mathrm{n}$ & $\%$ & $\mathrm{n}$ & $\%$ & $\mathrm{n}$ & $\%$ & & $1,615(0,580-$ \\
Negatif & 16 & 38,1 & 26 & 61,9 & 42 & 100 & & $4,503)$ \\
Positif & 8 & 27,6 & 21 & 72,4 & 29 & 100 & 0,506 & \\
\hline Total & 24 & 33,8 & 47 & 66,2 & 71 & 100 & & \\
\hline
\end{tabular}

Berdasarkan tabel 3 diperoleh bahwa dari 42 responden dengan sikap negatif terdapat $16(38,1 \%)$ responden yang tidak patuh minum obat sedangkan dari 29 responden dengan sikap positif terdapat $8(27,6 \%)$ responden yang tidak patuh minum obat. Hasil uji statistik chi square diperoleh $p$ value $=0,506$ maka dapat disimpulkan bahwa tidak ada hubungan yang signifikan antara sikap dengan kepatuhan minum obat. Juga diperoleh nilai POR 1,615 (0,580-4,503) artinya responden dengan sikap negatif berpeluang 1 kali untuk tidak patuh minum obat dibandingkan responden dengan sikap yang positif.

\section{Hubungan Dukungan Keluarga dengan Kepatuhan Minum Obat TB Paru}

Tabel. 4

Hubungan Dukungan Keluarga dengan Kepatuhan Minum Obat TB Paru

\begin{tabular}{|c|c|c|c|c|c|c|c|c|}
\hline \multirow{3}{*}{$\begin{array}{c}\text { Dukungan } \\
\text { Keluarga }\end{array}$} & \multicolumn{4}{|c|}{ Kepatuhan Minum Obat } & \multirow{2}{*}{\multicolumn{2}{|c|}{ Total }} & \multirow{3}{*}{$P$ Value } & \multirow{3}{*}{ POR CI $95 \%$} \\
\hline & \multicolumn{2}{|c|}{ Tidak Patuh } & \multicolumn{2}{|c|}{ Patuh } & & & & \\
\hline & $\mathrm{n}$ & $\%$ & $\mathrm{n}$ & $\%$ & $\mathrm{n}$ & $\%$ & & \\
\hline Tidak & 19 & 38,0 & 31 & 62,0 & 50 & 100 & \multirow{4}{*}{0,038} & \multirow{4}{*}{$\begin{array}{c}1,961 \\
(0,618- \\
6,226)\end{array}$} \\
\hline Ada & & & & & & & & \\
\hline Ada & 5 & 23,8 & 16 & 76,2 & 21 & 100 & & \\
\hline Total & 24 & 33,8 & 47 & 66,2 & 71 & 100 & & \\
\hline
\end{tabular}

Berdasarkan tabel 4 di atas diperoleh bahwa dari 50 responden yang tidak memiliki dukungan keluarga terdapat $19(38,0 \%)$ responden yang tidak patuh minum obat sedangkan dari 21 responden dengan dukungan keluarga terdapat $5(23,8 \%)$ responden yang tidak patuh minum obat. Hasil uji statistik chi square diperoleh $p$ value $=0,038$ maka dapat disimpulkan bahwa ada hubungan yang signifikan antara dukungan keluarga dengan kepatuhan minum obat. Juga diperoleh nilai POR 1,961 (0,618-6,226) 
artinya responden yang tidak didukung keluarga berpeluang 1 kali untuk tidak patuh minum obat dibandingkan responden yang memiliki dukungan keluarga.

\section{Hubungan Peran Petugas Kesehatan dengan Kepatuhan Minum Obat}

Tabel. 5

Hubungan Peran Petugas Kesehatan dengan

Kepatuhan Minum Obat TB Paru

\begin{tabular}{|c|c|c|c|c|c|c|c|c|}
\hline \multirow{3}{*}{$\begin{array}{c}\text { Peran } \\
\text { Petugas } \\
\text { Kesehatan }\end{array}$} & \multicolumn{4}{|c|}{ Kepatuhan Minum Obat } & \multirow{2}{*}{\multicolumn{2}{|c|}{ Total }} & \multirow{3}{*}{$P$ value } & \multirow{3}{*}{ POR CI 95\% } \\
\hline & \multicolumn{2}{|c|}{ Tidak Patuh } & \multicolumn{2}{|c|}{ Patuh } & & & & \\
\hline & $\mathrm{n}$ & $\%$ & $\mathrm{n}$ & $\%$ & $\mathrm{n}$ & $\%$ & & \\
\hline Tidak & 12 & 44,4 & 15 & 55,6 & 27 & 100 & & 4,440 \\
\hline Berperan & & & & & & & & $(1,303-$ \\
\hline Berperan & 12 & 27,3 & 32 & 72,7 & 44 & 100 & 0,026 & $14,857)$ \\
\hline Total & 24 & 33,8 & 47 & 66,2 & 71 & 100 & & \\
\hline
\end{tabular}

Berdasarkan tabel 5 di atas diperoleh bahwa dari 27 responden yang menyatakan petugas kesehatan tidak berperan terdapat $12(44,4 \%)$ responden yang tidak patuh minum obat sedangkan dari 44 responden yang menyatakan petugas kesehatan berperan terdapat $12(27,3 \%)$ responden yang tidak patuh minum obat. Hasil uji statistik chi square diperoleh $p$ value $=0,026$ maka dapat disimpulkan bahwa ada hubungan yang signifikan antara peran petugas kesehatan dengan kepatuhan minum obat. Juga diperoleh nilai POR 4,440 (1,303 - 14,857) artinya responden yang menyatakanpetugas kesehatan tidak berperan berpeluang 4 kali untuk tidak patuh minum obat dibandingkan responden yang menyatakan petugas kesehatan berperan.

\section{PEMBAHASAN}

Tuberkulosis Paru (TB Paru) merupakan penyakit menular yang disebabkan oleh infeksi bakteri mycobacterium tuberculosis. Sampai saat ini masih merupakan salah satu masalah kesehatan masyarakat di dunia. Pengobatan tuberkulosis memerlukan waktu yang relatif panjang dengan dua tahap, yaitu tahap awal (intensif) dan tahap lanjutan (Suryadi, 2019). Kepatuhan penderita sangat dibutuhkan untuk kesembuhan pasien tuberkulosis paru, jika pasien TB Paru tidak patuh minum obat atau sampai putus berobat maka akan menyebabkan pasien carier, sehingga akan menularkan penyakit TB Paru ke orang lain disekitarnya (Indrawaty, 2012).

Penyebab dari ketidakberhasilan pengobatan TB Paru adalah kepatuhan pasien selama pengobatan. Menurut penelitian Shalahuddin \& Sukmawan (2018) yang menunjukkan bahwa pengetahuan merupakan faktor yang berhubungan dengan kepatuhan minum obat TB Paru dengan nilai P 0,000 (OR : 13,375). Menurut penelitian Fitri (2018) sikap pasien TB Paru merupakan faktor yang mempengaruhi kepatuhan pasien TB Paru minum obat di Wilayah Kerja Puskesmas Sadabuan Kota Padang Sidimpuan dengan nilai $\mathrm{p}=0,000$.

\section{Hubungan Pengetahuan dengan Kepatuhan Minum Obat Pasien TB Paru}

Berdasarkan hasil penelitian dengan uji chi square diperoleh $P$ value yaitu 0,005. Hal ini menunjukkan $P$ value $<$ dari 0,05 yang berarti ada hubungan yang bermakna antara pengetahuan dengan kepatuhan minum obat pasien TB Paru di Wilayah Kerja Puskesmas Siak Hulu II. Menurut Notoatmodjo (2012) pengetahuan merupakan hasil 
dari penginderaan manusia atau hasil tahu. Maka pengetahuan yang dimiliki seseorang dapat diaplikasikan dengan baik untuk proses pencarian informasi.

Pengetahuan yang dimiliki responden yang terkena TB Paru yang mau mencari informasi mengenai kepatuhan minum obat, maka pengetahuan dari responden TB Paru dapat diaplikasikan dengan baik sehingga dapat bersikap baik dan patuh menjalani proses pengobatan. Penelitian ini sejalan dengan penelitian yang dilakukan oleh Samah (2015) yang menunjukkan bahwa ada hubungan pengetahuan dengan kepatuhan minum obat TB Paru.

Pengetahuan seseorang berhubungan dengan perilaku seseorang, jika pengetahuan seseorang rendah maka perilaku seseorang akan cenderung ke arah yang tidak baik begitu juga sebaliknya jika pengetahuan seseorang tinggi maka perilaku akan cenderung lebih baik. Dalam penelitian ini diketahui bahwa responden tidak mengetahui cara pengobatan TB paru dan tahap minum obat TB paru. Dari hasil penelitian dilapangan sebagian besarresponden dengan tingkat pendidikan SD dan SMP, hal ini menyebabkan responden tidak mengetahui tahapan meminum obat TB Paru.

\section{Hubungan Sikap dengan Kepatuhan Minum Obat TB Paru}

Berdasarkan hasil analisis chi square diperoleh $\mathrm{p}$ value 0,506 hal ini menunjukkan $p$ value $>$ dari 0,05 yang berarti tidak ada hubungan sikap responden dengan kepatuhan minum obat TB paru di Wilayah Kerja Puskesmas Siak Hulu II. Sikap merupakan salah satu hal yang penting untuk meningkatkan kesadaran bahwa keadaan responden TB paru sangat perlu melakukan pemeriksaan kepada petugas kesehatan, agar selama dalam menjalani proses pengobatan responden dapat berpeluang untuk sembuh, kondisi ini sesuai dengan teori Notoatmodjo (2012) sikap merupakan reaksi atau proses kesiapan untuk bereaksi terhadap objek lingkungan tertentu sebagai suatu penghayatan terhadap objek.

Penelitian ini sejalan dengan penelitian Pagayang et al., (2019) menyatakan bahwa tidak ada hubungan sikap dengan kepatuhan minum obat. Hasil penelitian ini juga menyatakan bahwa jika sikap yang baik mampu meningkatkan kepatuhan minum obat penderita TB Paru.

Berdasarkan hasil analisis hal ini menunjukkan bahwa semakin negatif sikap seseorang maka perilaku seseorang tidak baik pula dalam pengobatan TB Paru, dalam penelitian ini responden lebih banyak sikap negatif dari pada sikap positif, hal ini juga berkaitan dengan pengetahuan responden yang rendah, karna untuk membentuk sikap seseorang terhadap pengobatan TB Paru tidak lepas dari tingkat pengetahuan. Dengan pengetahuan yang baik maka responden dapat bersikap positif dalam proses pengobatan TB Paru. Maka dari penelitian ini sikap responden lebih cenderung negatif dimana bila tidak ada dahak lagi dianggap sudah sembuhatau menggangap tidak meminum obat responden akan sembuh sendiri.

Penelitian Shalahudin \& Sukmawan (2018) diperoleh kepatuhan minum obat pasien TB diperoleh hasil sebagian besar responden $(63,33)$ patuh minum obat dan hampir setengahnya dari responden $(26,67 \%)$ tidak patuh minum obat. Ketidakpatuhan menurut Erawatyningsih \& Purwanta (2009); Nhavoto et al., (2017) terjadi bila pemahaman tentang instruksi yang salah atau tidak paham, kurangnya kualitas interaksi dengan profesional kesehatan, tidak ada dukungan keluarga atau kurangnya keyakinan sikap dan kepribadian. Keempat faktor diatas menurut Notoatmojo (2012) dapat di perbaiki dengan pendidikan yaitu memberikan informasi tentang penyakit dan pengobatan TB disamping dukungan profesional dan keluarga serta memodifikasi gaya 
hidup sehat sehingga terbentuk kesadaran yang tinggi dari pasien untuk patuh minum obat dalam situasi bagaimanapun.

\section{Hubungan Dukungan Keluarga dengan Kepatuhan Minum Obat}

Berdasarkan hasil analisis chi square diperoleh pvalue yaitu 0,038 berarti tidak ada hubungan dukungan keluarga pada pasien TB paru di wilayah Kerja Puskesmas Siak Hulu II. Dukungan kelurga sangat membantu dalam meningkatkan kepatuhan penderita TB paru, maka dengan adanya dukungan keluarga penderita TB Paru tidak bisa mangkir dari keharusan untuk minum obat, selain itu keluarga juga memberikan motivasi sehingga penderita TB Paru semangat menjalni pengobatan, dukungan keluarga adalah sikap, tindakan, dan penerimaan keluarga terhadap penderita yang sakit (Friedman dalam Akhmadi, 2009).

Penelitian ini sejalan dengan penelitian Pitters et al., (2018) menjelaskan bahwa ada hubungan dukungan keluarga dengan kepatuhan minum obat. Berdasarkan hasil analisis terdapat hubungan antara dukungan keluarga dengan kepatuhan minum obat, dalam penelitian ini responden tidak dapat dorongan untuk berobat dari keluarga dan responden tidak dapat dorongan dari keluarga untuk mengingatkan menelan obat sesuai jam yang telah ditentukan, penderita TB paru lebih beresiko untuk mengalami tidak patuh minum obat dibandingkan penderita TB paru yang dapat dorongan dari keluarga maka responden patuh minum obat dan memeriksa penyakit TB paru.

\section{Hubungan Peran Petugas Kesehatan dengan Kepatuhan Minum Obat}

Berdasarkan hasil analisis chi square diperoleh p value yaitu 0,026 yang berarti tidak ada hubungan peran petugas kesehatan dengan kepatuhan minum obat pasien TB Paru di wilayah kerja Puskesmas Siak Hulu II. Untuk mendukung keberhasilan pengobatan penderita TB paru peran serta dari petugas kesehatan sangat besar, salah satunya adalah memberikan informasi mengenai penyakit TB paru, memotivasi penderita TB paru agar bersabar dalam menjalani proses pengobatan dalam jangka waktu yang cukup lama, dan juga memotivasi penderita TB Paru agar tidak putus asa untuk melakukan tindakan pemeriksaan secara rutin. Penelitian ini sejalan dengan penelitian Ali (2019) menyatakan bahwa ada hubungan peran petugas kesehatan dengan kepatuhan minum obat TB Paru.

Berdasarkan hasil analisis terdapat hubungan antara peran petugas kesehatan dengan kepatuhan minum obat dalam penelitian ini responden telah mendapatkan informasi tentang tahap-tahap minum obat TB Paru, petugas kesehatan juga berperan dalam mengingatkan pasien untuk pengambilan obat dan pemeriksaan penyakit TB paru pada saat pengambilan obat petugas kesehatan menjelaskan tahap-tahap minum obat TB paru dan petugas kesehatan juga mengingatkan pengambilan obat selanjutnya. Hal ini sesuai dengan penelitian Dermawanti et al., (2014) yang menunjukkan bahwa sikap mendukung petugas kesehatan memberi pengaruh terhadap kepatuhan pasien dimana pasien mendapat dukungan motivasi dari petugas kesehatan untuk selalu tepat waktu mengambil obat ke puskesmas dan selalu memperhatikanperkembangan kesehatan pasien, sehingga pasien merasa diperhatikan oleh petugas dan menerima semua anjuran petugas selama pengobatan. 


\section{SIMPULAN}

Berdasarkan analisis bivariat dari 4 variabel terdapat 3 variabel yang berhubungan dengan kepatuhan minum obat TB paru di Wilayah Kerja Puskesmas Siak Hulu II yaitu pengetahuan, dukungan keluarga, dan peran petugas kesehatan dan 1 variabel yang tidak berhubungan yaitu sikap.

\section{SARAN}

Petugas puskesmas khususnya pemegang program TB Paru agar mengingatkan pasien dalam proses pengobatan dan menjelaskan tahap-tahap minum obat TB Paru. Petugas sebaiknya menelpon atau menghubungi penderita TB Paru jika tidak mengambil obat pada waktu yang telah ditentukan serta mengunjungi pasien jika tidak datang mengambil obat ke Puskesmas Siak Hulu II.

\section{DAFTAR PUSTAKA}

Akhmadi, A. (2009). Tuberkulosis Paru . www.medicastore.com

Ali, S. M. (2019). Faktor-Faktor yang Berhubungan dengan Kepatuhan Berobat Penderita TB Paru di Wilayah Kerja Puskesmas Siko Kota Ternate. Jurnal Kesehatan Masyarakat, 2(1), 1-10

Dermawanti. D., Rochadi, R. K., \& Tukiman, T. (2014). Hubungan Komunikasi Interpersonal Petugas Kesehatan terhadap Kepatuhan Pasien Menjalani Pengobatan TB Paru di Puskesmas Sunggal Medan Tahun 2014. Kebijakan, Promosi Kesehatan dan Biostatistik, 1(2), 1-10

Erawatyningsih, E., \& Purwanta, H. S. (2009). Faktor-Faktor yang Mempengaruhi Ketidakpatuhan Berobat pada Penderita Tuberkulosis Paru. Berita Kedokteran Masyarakat, 25(3), 117

Fitri, L. D., Marlidawani, J., Purba, A. (2018). Kepatuhan Minum Obat pada Pasien Tuberkulosis Paru. Jurnal Kesehatan Masyarakat, 7(1), 33-42. https://journals.stikim.ac.id/index.php/jikm/article/view/50

Indrawaty, L. (2012). Hubungan Motivasi Kesembuhan dengan Kepatuhan Minum Obat Tuberkulosis Paru di Ruang Rawat Inap Mawar RSUD Kota Bekasi tahun

Kementerian Kesehatan. (2014). Pedoman Pengendalian Tuberlosis. Jakarta

Kementerian Kesehatan. (2018). Data dan Informasi Kementrian Kesehatan RI. Jakarta

Nhavoto, J. A., Grönlund, Å., \& Klein, G. O. (2017). Mobile Health Treatment Support Intervention for HIV and Tuberculosis in Mozambique: Perspectives of Patients and Healthcare Workers. PloS one, 12(4), e017605

Notoadmodjo, S. (2012). Promosi Kesehatan dan Ilmu Perilaku. Jakarta: Rineka Cipta

Pagayang, Z. I., Umboh, J. M. L A., Manapawang, A. L. (2019). Faktor-Faktor yang Berhubungan dengan Kepatuhan Minum Obat pada Penderita Tuberkulosis Paru di Puskesmas Kamonji Kota Palu. Graha Medika Nursing Jurnal, 2(1), 63-71

Pitters, T, S., Kandou, G. D., \& Nelwan, J. E. (2018). Dukungan Keluarga dalam Hubungan dengan Kepatuhan Minum Obat Pasien Tuberculosis Paru di Puskesmas Ranotana Weru. Jurnal Kesmas, 7(5), 1-5. https://ejournal.unsrat.ac.id/index.php/kesmas/article/view/22140

Samah, A. (2015). Faktor-Faktor yang Berhubungan dengan Kepatuhan Minum Obat pada Pasien TB Paru di Wilayah Kerja Puskesmas Rokan IV Koto I Kabupaten Rokan Hulu Tahun 2015. STIKes Hang Tuah: Pekanbaru 
Shalahudin, I., \& Sukmawan, S. I. (2018). Hubungan antara Pengetahuan Pasien tentang Tuberkulosis dengan Kepatuhan Minum Obat di Poliklinik DOTS RSUD dr. Slamet Garut. HJK: Holistik Jurnal Kesehatan, 12(2), 68-73. http://ejurnalmalahayati.ac.id/index.php/holistik/article/view/6/4

Suryadi, M. A., Grace, D. K., Wulan, P. J., \& Kaunang, K. (2019). Faktor-Faktor yang Berhubungan dengan Kepatuhan Berobat Penderita TB Paru di Wilayah Kerja Puskesmas Siko Kota Ternante. Jurnal Kesehatan, 2(1), 72

World Health Organization. (2017). Global Tuberculosis Report 2017, 15-49. Geneva 